\title{
Preparing Clinical Laboratory Science Students with Teaching Skills
}

\author{
JEANNE M ISABEL
}

\begin{abstract}
Training clinical laboratory science (CLS) students in techniques of preparation and delivery of an instructional unit is an important component of all CLS education programs and required by the national accrediting agency. Participants of this study included students admitted to the CLS program at Northern Illinois University and enrolled in the teaching course offered once a year between the years of 1997 and 2009. Courses on the topic of "teaching" may be regarded by CLS students as unnecessary. However, entry level practitioners are being recruited to serve as clinical instructors soon after entering the workforce. Evaluation of the data collected indicates that students are better prepared to complete tasks related to instruction of a topic after having an opportunity to study and practice skills of teaching. Mentoring CLS students toward the career role of clinical instructor or professor is important to maintaining the workforce.
\end{abstract}

INDEX TERMS: clinical instruction, clinical laboratory science curriculum, mentoring clinical instructors.

Clin Lab Sci 2010;23(3)Suppl:3-3

Jeanne M. Isabel, MSEd, MLS, SH ${ }^{C M}$, Clinical Laboratory Sciences, Northern Illinois University

Address for Correspondence: Jeanne M. Isabel, MSEd, $M T(A S C P), S H(B O C)$, Clinical Laboratory Sciences, DuSable 163, Northern Illinois University, 815-7536330, jisabel@niu.edu

\section{INTRODUCTION}

Training clinical laboratory science students in techniques of preparation and delivery of an instructional unit is an important component of all education programs and required by the national accrediting agency. In order to earn the title of Clinical Laboratory Scientist (CLS), one must master a background rich in the subjects of biology, chemistry and statistics to name a few, before engulfing in the more rigorous curriculum reserved for the major in CLS. Once on that path the CLS student encounters discipline specific courses along with more general subjects of research, management and teaching. Entry level practitioners must be able to perform not only technical procedures but to fulfill the role of clinical educator once in the workforce. Although the student may find the general subjects less interesting and perhaps unnecessary while in the academic environment, the value of this instruction becomes relevant in real practice.

The purpose of this paper is to evaluate CLS student preparation for teaching following a course in this subject. Participants of this study included students admitted to the CLS program at Northern Illinois University (NIU) and enrolled in the teaching course offered once a year between the years of 1997 and 2009. A cohort of data collected from groups of CLS course participants in the form of pre and post-course surveys were evaluated to provide insight to student perceived expectations of preparing an instructional unit for teaching.

The projected conclusion of this study is that CLS students are familiar with the tools and techniques of preparation and delivery of an instructional unit after completion of a course on teaching. Mastery of these skills develops with practice and mentoring of new educators requires directing potential candidates to resources available post academically.

Over the past few years, individuals seeking the profession of clinical laboratory science include both 


\section{CLINICAL PRACTICE}

those individuals eager to serve the public in a healthcare setting and those looking for adventure as a forensic scientist. Completion of both the baccalaureate and associate degrees for laboratory science attract student populations made up of adults of the traditional college age as well as nontraditional aged individuals looking for an alternative profession in this time of economic stress. All students are faced with juggling the role of academics versus personal life. Support from family and community, both emotionally and financially, help retain students in the academic environment. An interesting observation of today's workforce in laboratory science is that the majority of practitioners continue to be women.

Clinical didactic material and basic laboratory skills are developed during the early phase of the CLS major with the honing of those academic and laboratory skills, along with practice towards competence, being accomplished during training in hospital laboratories. As cited in Harmening "Teaching hospitals are made up of a variety of personnel and many individuals are required to provide instruction as part of their job without any formal training in education." ${ }^{1}$ In order to avoid the problem of unprepared clinical instructors, the CLS curriculum has been revised over time to include a course on developing an instructional unit. Undergraduate students may not realize that as little as one or two years after graduation, they may be teaching at the clinical site.

\section{Accreditation requirements and implementation}

College, university and hospital programs are encouraged to be accredited by the National Accrediting Agency for Clinical Laboratory Sciences (NAACLS). In order to maintain standards of excellence in CLS education the curricular standards of this accreditation body for the profession states that the CLS program must have "education techniques and terminology sufficient to train/educate users and providers of laboratory services." ${ }^{2}$ In complicance with this standard, students in the CLS program at NIU are required to complete the course, AHCD 440 Introduction to Teaching in Allied Health Professions, for one hour of credit. The course content includes explanations of educational learning domains and taxonomy levels of difficulty. Discussions of different methods to match the level of instruction to the needs of the learner encourages the student to relate past academic experiences to new ideas related to instruction. Learning style inventories are used in the class to demonstrate the diversity in which adult learning is accomplished. Several intermediate assignments culminate in the final project of designing a presentation with accompanying objectives and multiple choice test questions to match the objectives. Students are encouraged to select a topic which interests them to prepare a presentation outline which contains objectives and assessement tools incorporating all three learning domains of cognitive, affective and psychomotor. In addition, levels of difficulty (taxonomy) help define the progress of learner from beginner to expert as described by Dr. Benjamin Bloom for the cognitive domain. In order to assist with management of the assignments, students select a class peer to review their drafts and offer suggestions for improvement. Finally the student prepares a learning activity suitable for delivery to an assortment of audiences, keeping in mind the media support needed for instruction in a variety of settings.

\section{METHODS}

\section{Characteristics of Participants}

The population for this study consisted of course enrollment of between 16 to 34 students per course over the twelve year period. The larger number of students per class section occurred in the last 5 years with more than 25 students in each section. Each group consisted of an average of $80 \%$ female and 20\% male students. The age of students ranged from 21 years to about 40 years of age, the majority being traditional college aged students.

\section{Description of procedure}

In order to measure the student's ability to accomplish the objectives of the teaching course, surveys were developed for participants to complete on the first day of class, and again on the last day. (Table 1 and 2). Survey questions were designed specifically for assessment of the student's perception of abilities in educational tasks prior to instruction and at the completion of instruction. Both the pre and postcourse surveys contain fifteen questions worded identically. In addition, there are eight questions on the 


\section{CLINICAL PRACTICE}

Table 1: Pre-Evaluation for AHCD 440 Introduction to Teaching in Allied Health Professions

The information you provide below will be used to improve the quality of instruction. Data from the survey may be compiled to use for presentations or publications related to CLS student's perception of education in the curriculum. You are under no obligation to complete this form. Do not place your name on this form to protect your anonymity. Completion of this form will not impact your grade for this course. The questions below refer to class activities for AHCD 440 related to peer review, communication, preparation of necessary materials for instructing a unit. Thank you for your cooperation in completion of this survey. Circle the number that best applies.

\begin{tabular}{|c|c|c|c|c|c|}
\hline At the present time I can effectively: & $\mathrm{NA}^{*}$ & $\begin{array}{l}\text { Strongly } \\
\text { Disagree }\end{array}$ & Disagree & Agree & $\begin{array}{c}\text { Strongly } \\
\text { agree }\end{array}$ \\
\hline 1. Select a presentation topic & 0 & 1 & 2 & 3 & 4 \\
\hline 2. Write educational objectives for the cognitive domain & 0 & 1 & 2 & 3 & 4 \\
\hline 3. Write educational objectives for the psychomotor domain & 0 & 1 & 2 & 3 & 4 \\
\hline 4. Write educational objectives for the affective domain & 0 & 1 & 2 & 3 & 4 \\
\hline 5. Prepare a content outline for a presentation & 0 & 1 & 2 & 3 & 4 \\
\hline 6. Write level 1 multiple choice test questions (recall) & 0 & 1 & 2 & 3 & 4 \\
\hline 7. Write level 2 multiple choice test questions (application) & 0 & 1 & 2 & 3 & 4 \\
\hline 8. Write level 3 multiple choice test questions (problem-solving) & 0 & 1 & 2 & 3 & 4 \\
\hline 9. Select and use appropriate, recent references to prepare a presentation & 0 & 1 & 2 & 3 & 4 \\
\hline 10. Prepare handout materials for an oral presentation & 0 & 1 & 2 & 3 & 4 \\
\hline 11. Prepare an oral presentation & 0 & 1 & 2 & 3 & 4 \\
\hline 12. Prepare graphics and visual aids for a presentation & 0 & 1 & 2 & 3 & 4 \\
\hline 13. Select appropriate audio/visual equipment for a presentation & 0 & 1 & 2 & 3 & 4 \\
\hline 14. Use audio/visual equipment effectively & 0 & 1 & 2 & 3 & 4 \\
\hline 15. Consult with peers to improve educational materials & 0 & 1 & 2 & 3 & 4 \\
\hline
\end{tabular}

${ }^{*} \mathrm{NA}=$ Not applicable

Table 2: Post-Evaluation for AHCD 440 Introduction to Teaching in Allied Health Professions

\begin{tabular}{|c|c|c|c|c|c|}
\hline At the present time I can effectively: & $\mathrm{NA}^{*}$ & $\begin{array}{l}\text { Strongly } \\
\text { Disagree }\end{array}$ & Disagree & Agree & $\begin{array}{c}\text { Strongly } \\
\text { agree }\end{array}$ \\
\hline 1. I expect to have teaching responsibilities in the first CLS job I have after graduation & n 0 & 1 & 2 & 3 & 4 \\
\hline 2. I expect to have teaching responsibilities at some time during my CLS career & 0 & 1 & 2 & 3 & 4 \\
\hline 3. This course will benefit me in the first job I will have after graduation & 0 & 1 & 2 & 3 & 4 \\
\hline 4. The course has increased my understanding of education principles & 0 & 1 & 2 & 3 & 4 \\
\hline 5. This course has increased my ability to teach & 0 & 1 & 2 & 3 & 4 \\
\hline 6. The readings for this course were appropriate to my level of understanding & 0 & 1 & 2 & 3 & 4 \\
\hline 7. The work required for the course was appropriate for the time available & 0 & 1 & 2 & 3 & 4 \\
\hline 8. Select a presentation topic & 0 & 1 & 2 & 3 & 4 \\
\hline 9. Write educational objectives for the cognitive domain & 0 & 1 & 2 & 3 & 4 \\
\hline 10. Write educational objectives for the psychomotor domain & 0 & 1 & 2 & 3 & 4 \\
\hline 11. Write educational objectives for the affective domain & 0 & 1 & 2 & 3 & 4 \\
\hline 12. Prepare a content outline for a presentation & 0 & 1 & 2 & 3 & 4 \\
\hline 13. Write level 1 multiple choice test questions (recall) & 0 & 1 & 2 & 3 & 4 \\
\hline 14. Write level 2 multiple choice test questions (application) & 0 & 1 & 2 & 3 & 4 \\
\hline 15. Write level 3 multiple choice test questions (problem-solving) & 0 & 1 & 2 & 3 & 4 \\
\hline 16. Select and use appropriate, recent references to prepare a presentation & 0 & 1 & 2 & 3 & 4 \\
\hline 17. Prepare handout materials for an oral presentation & 0 & 1 & 2 & 3 & 4 \\
\hline 18. Prepare and oral presentation & 0 & 1 & 2 & 3 & 4 \\
\hline 19. Prepare graphics and visual aids for a presentation & 0 & 1 & 2 & 3 & 4 \\
\hline 20. Select appropriate audio/visual equipment for a presentation & 0 & 1 & 2 & 3 & 4 \\
\hline 21. Use audio/visual equipment effectively & 0 & 1 & 2 & 3 & 4 \\
\hline 22. Consult with peers to improve educational materials & 0 & 1 & 2 & 3 & 4 \\
\hline
\end{tabular}

23. Rate the overall value of this course

What parts of the course do you feel will most benefit you in the future? What parts of the course do you feel will least benefit you in the future? If I could change this course I would: 


\section{CLINICAL PRACTICE}

post survey related to completion of the course and an area for comments.

Results of the surveys completed from 1997 to 2009 were evaluated with descriptive statistics. Students completed the survey anonymously and there is no record to match pre and post surveys to individuals for statistical analysis. However, summative data from the responses provide useful insight to student perceptions regarding the course designed to "teach them to teach."

The pre and post-course survey established for this education course in the late 1990s was designed to assess the student's perception of teaching concepts prior to, and at the completion of, a course covering the education process. Questions on the pre-course survey were numbered from 1-15 with a selection of 0 -not applicable, 1-strongly disagree, 2- disagree, 3- agree, 4strongly agree. The series of questions were prefaced by the statement "at the present time I can effectively." A selection of "disagree" by the student on any item, indicates that he/she did not feel comfortable performing the tasks stated. Survey items ranged from selection of a topic and preparing an outline for presentation, to writing objectives in cognitive, affective and psychomotor domains. Other items relate to writing multiple choice test questions at three taxonomy levels while identifying the learning domain for each. Finally, statements referring to the student's awareness of audio visual equipment needs and use were assessed. There were a total of 264 pre-course surveys analyzed with an average of 22 per year.

The post-course survey was given on the last day of class, after the student had completed all written assignments for the course and participated in class discussions. It included the same fifteen questions from the pre-survey. There are eight additional questions related to expectations of having teaching responsibilities once graduated, usefulness of the course in understanding education principles and ability to teach along with an assessment of the course overall. There were a total of 242 post-course surveys evaluated for an average of 20 per year. An opportunity for subjective comments on the post-course survey included describing the most and least beneficial components of the course and recommendations for change.

\section{RESULTS}

By looking at the surveys collected in the teaching class at NIU some distinctive observations and patterns are recognized. Figure 1 is a graphic illustration of three critical statements on the post course survey, namely expectation of teaching during the student's career as a CLS, effective ability to teach after the course and overall course usefulness. The first bar in Figure 1 shows a comparison over the years of responses to the question of whether the student expects to have teaching responsibilities at some time during his/her CLS career. There appears to be a rather steady increase in the average for most years holding between 2.45 and 3.64 which is between "disagree" and "agree," with a drop in 2002 and 2006. The response from the spring 2009 course is the highest average of all years with a 3.64 which places the response between "agree" and "strongly agree." This is most likely due to emphasis in the class that there are many university and clinical instructors reaching retirement age and the need for instructors is constantly increasing.

The second bar of this graph indicates an average response to the question "this course has increased my ability to teach." The averages vary between 2.50 and 3.23 which indicate responses between "disagree" to "agree" with only four of the yearly averages above 3.00 (agree). Because many CLS students equate teaching with standing in front of a classroom, they do not perceive themselves performing this task. In addition, the average numbers reflect the concept that actual practice in teaching is the best way to improve one's self-confidence in the ability to teach.

The third column of the graph is an average of the responses to the question of "overall value of the course." The number range of 2.78 (1997) - 3.56 (2009) reflects the student's recognition of the value of the course.

Figure 2 is showing a comparison of the averages from the pre and post surveys in response to three questions referring to the student's ability to write educational objectives using learning domains of cognitive, affective 


\section{CLINICAL PRACTICE}

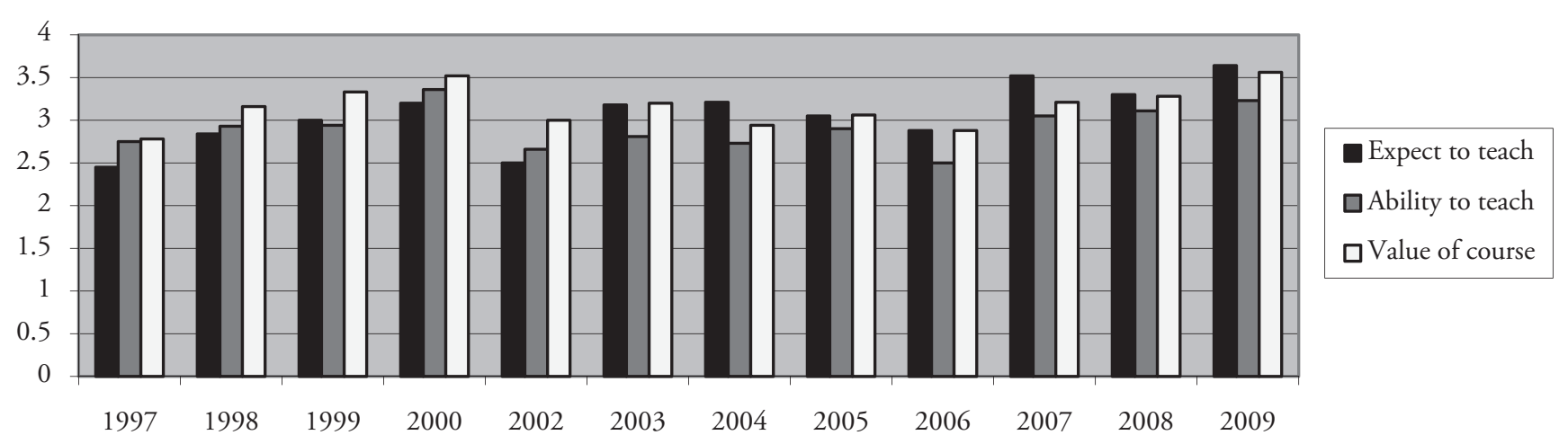

Figure 1. Comparison of responses over the years of student's expectations and abilities to teach in CLS and the values of the teaching course.

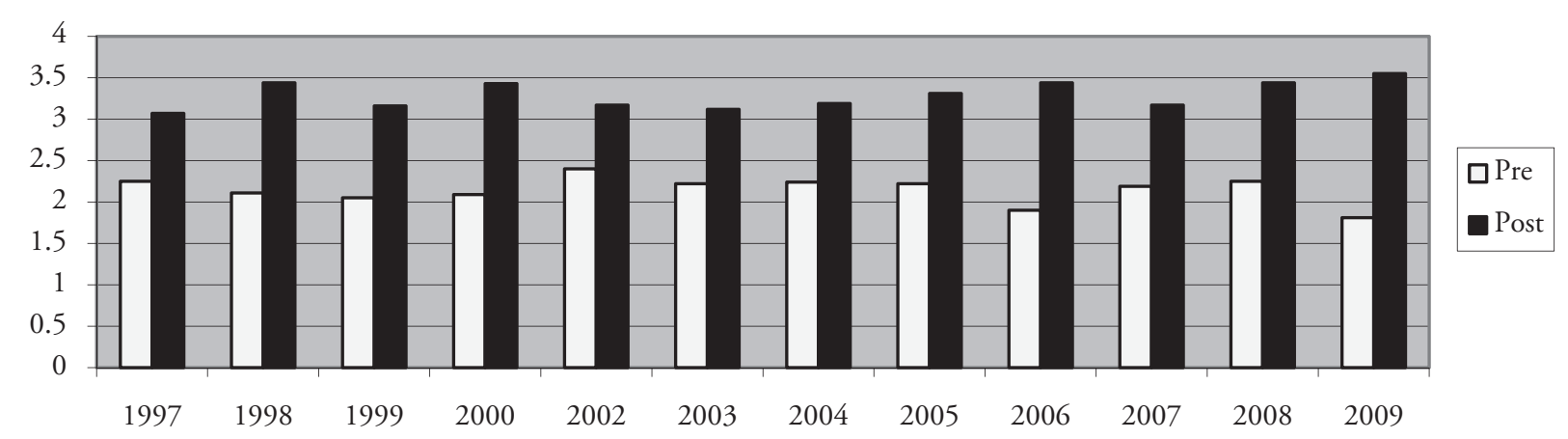

Figure 2. Writing objectives in cognitive, affective and psychomotor domains; comparison of pre and post surveys.

and psychomotor. An average of all the pre course surveys for the years listed was 2.14, with five years having an average below this number. Certainly the concepts of learning domains and principles of writing good objectives for a lesson were unfamiliar territory. In contrast to the pre-surveys, the post surveys all indicate that on completion of the course the student can perform this task. The average difference in values given for the pre and post responses for these questions is 1.15 which indicates an improvement from disagreeing with the ability to write objectives, to more than agreeing on this ability.

Figure 3 is comparing the pre and post survey response averages to the three questions concerning writing multiple choice test questions for the recall, application and problem-solving levels. As seen in figure two for writing objectives, this graph also shows distinctive improvement of the post-course average to the precourse response. It is interesting to note that the range between pre and post values is only 0.80 which is considerably less than that of the questions related to writing objectives. A possible interpretation may be that students think it rather easy to write good multiple choice test questions until they have to do it. Since the average on the post responses was only 3.38 , there is agreement that improvement in ability occurred but students did not consider their ability to be very effective at the time of course completion. Most educators, especially those who have been teaching for many years, would agree that much practice is needed before mastering the task of expert exam question writer.

Figure 4 provides a visual representation of the pre and post survey averages in response to questions about preparing graphics and visual aids for a presentation, selection of audio-visual (AV) equipment and use of AV equipment effectively. The average difference of these pre and post responses was the smallest of all compari- 


\section{CLINICAL PRACTICE}

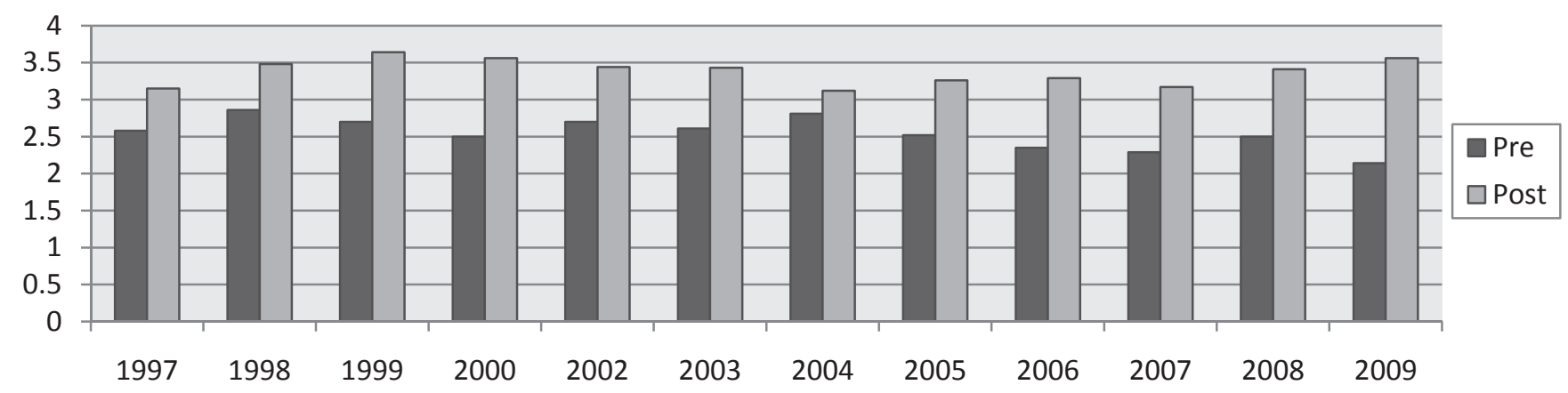

Figure 3. Writing Test questions in all levels of cognitive domain; comparison of pre and post surveys

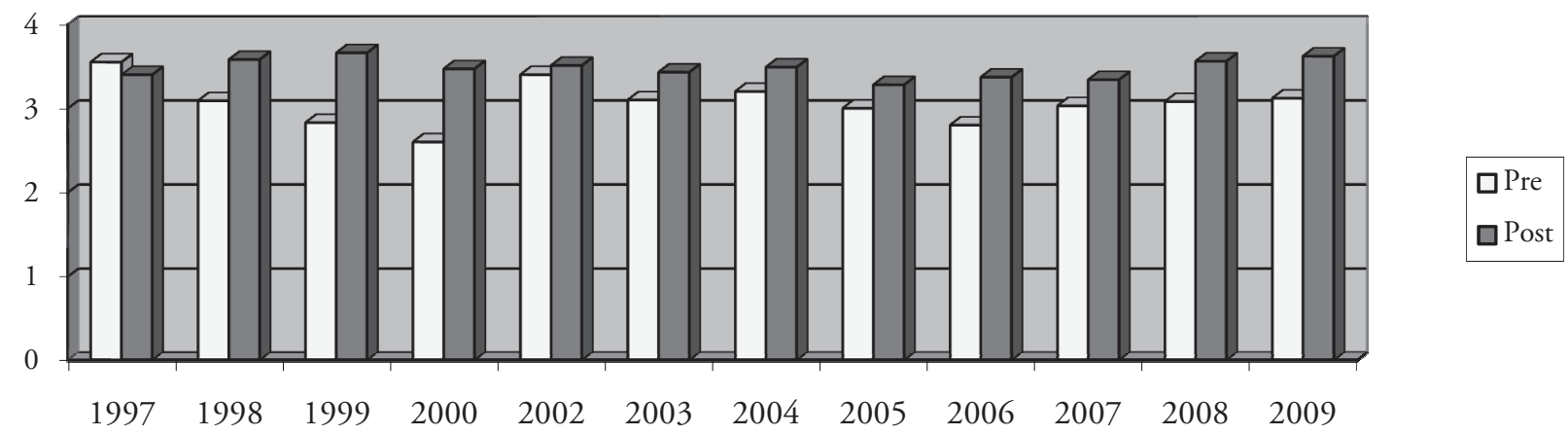

Figure 4. Selection and use of AV equipment; comparison of pre and post surveys.

sons at 0.41 . This is most likely due to the fact that adult learners today have grown up with computer technology and are able to adapt technology to educational assignments fairly easily.

The open ended comments on the post survey asked for the most beneficial and least beneficial part of the course. Of 242 surveys completed, 159 students added comments (41\%).

Many of the most beneficial comments were similar to the examples listed: "the test questions that we were to prepare. If you can teach a topic then you should be able to have a firm enough grasp to ask questions."

"the objectives and test questions parts because I had no idea how to write objectives or test questions. I would just write random questions and hoped it worked"

"the ability to make presentations and write objectives"
At least $11 \%$ of the comments listed learning domains as a new concept and beneficial outcome.

As might be expected for each comment listing an activity as most beneficial is a matching least beneficial response. Note some responses:

\section{"writing test questions" \\ "peer interaction" \\ "learning all the domains, they are interchangeable" "since I don't plan on going into the education major, this would not be useful, unless I plan on it later"}

As noted by the last two comments, there is some disconnect between the objectives of the course and the student perceived outcome. The fact that considerably more students found the three main assignments as most beneficial instead of least beneficial was encouraging. 


\section{CLINICAL PRACTICE}

\section{DISCUSSION}

This study provides evidence that students in healthcare majors benefit from receiving instruction in subjects other than the sciences. By incorporating concepts that may be practiced once the student is a certified professional, the uncertainty of what to expect when asked to "provide an instructional unit" is not so frightening.

Other than stating accreditation requirements, justifying courses on education techniques, research and management as relevant to the student who plans to work "on the bench" for a few years may be a challenge. A report by Behan on teaching research design to CLS students describes opportunities that develop using different practice components in the curriculum. ${ }^{3}$ By emphasizing the developing roles of laboratory professionals and career opportunities, preparation in a variety of special skills is extremely important. The need for clinical laboratory science professors/instructors to be organized and able to present clear and concise objectives was emphasized throughout the course in this study.

During clinical practice students work hand in hand with preceptors or "bench instructors" and see the opportunity of utilizing the information delivered in the "teaching" course. Woeste and Barham have stated "professional practice experience offers an intense applied delivery where the student can begin to develop the skills and form the dispositions needed to become a successful entry-level professional when they graduate." ${ }^{4}$ The student learns that it is not just the didactic and technical skills that were developed in the university setting that are needed in the workplace. The idea of transitioning from student on Friday to professional in the workplace on Monday is somewhat mind- boggling to some individuals. In reality, the development of professional skills takes place over a life time.

In order to groom young professionals for educational roles, there must be support for preceptors (also known as clinical instructors). New preceptors often lack confidence in the role. Once comfortable in the positions, they "gain a sense of contribution to the profession and recognize that they are shaping the next generation of practitioners." ${ }^{5}$ Since there are several technologists in the workplace who have not had the advantage of a course in methods for constructing an instructional unit, the College of Health and Human Sciences at NIU has offered a workshop over the last three years to benefit clinical instructors in all health education specialties. The problems and issues confronting clinical education of students are not unique to CLS. Although there are different ways of delivering clinical instruction, there are many similarities and the workshop audience is very perceptive to adapting ideas presented by the speakers. In the most recent workshop, NIU alumni of the CLS program who are now clinical instructors commented on the benefit of the "teaching" course for their current role.

\section{CONCLUSION}

Filling the shortage of clinical laboratory science practitioners and mentoring professionals for the role of educator is a top priority of the laboratory science community. CLS programs strive to prepare students for all roles in their professional career. In some cases, the success of the learning and development of the individual depends on that person's motivation, commitment and ability to be self-directed. The clinical laboratory scientist labors away analyzing specimens, identifying unknown organisms and providing data that enables physicians to make intelligent decisions regarding treatment and care of a patient. Recognition of the value of this profession continues to be an issue.

Evaluation of data from the research presented here indicates that CLS students typically are not exposed to learning theories and concepts related to teaching in adult education. After completion of an introductory course and practice with writing and presentation skills, most students will have more confidence to engage in teaching activities. Mentoring young professionals to become involved in professional societies and provide presentations at state and national meetings is an excellent way to promote competence in the skills being developed at the university or hospital setting.

Additional studies would be useful by charting the pre and post surveys for each group and recording some demographic data such as gender and age. The fact that 


\section{CLINICAL PRACTICE}

students came away from the course with recognition of new abilities in the area of teaching is encouraging. Many of the CLS students of today will find themselves utilizing these skills early in their careers.

\section{REFERENCES}

1. Harmening, D. Education and Training: Practical Tips for educators and trainers. In E.A. Zeibig (Ed.), Laboratory Management, Principles \& Practice (pp. 148-58). Upper Saddle River, NJ: Prentice Hall; 2002.
2. NAACLS DMS accreditation information: standards and documents for CLS/MT. (n.d.)., Availble from http://www. naacls.org/docs/Section3_CLS-MT.pdf. Accessed 2009 Sept 23.

3. Behan, KJ. Teaching research design and practice one bite at a time in the MT/CLS curriculum. Lab Med, 2007; 38(10), 582-6.

4. Woeste, LA., \& Barham, BJ. The signature pedagogy of clinical laboratory science education: the professional practice experience. Lab Med, 2006; 37(10), 591-2.

5. Giordano, L., Mahalik, A., \& Bartlett, D. Mentors at the bench: supporting clinical educators. Can J Med Lab Sci, 2007; 69(6), 242-5.

The peer-reviewed Clinical Practice Section seeks to publish case studies, reports, and articles that are immediately useful, are of a practical nature, or contain information that could lead to improvement in the quality of the clinical laboratory's contribution to patient care, including brief reviews of books, computer programs, audiovisual materials, or other materials of interest to readers. Direct all inquiries to Libby Spence, PhD, CLS(NCA), Clin Lab Sci Clinical Practice Editor, University of Mississippi Medical Center, 2500 North State Street, Jackson, MS 39216, lspence@umc.edu.

Clinical Laboratory Science encourages readers to respond with thoughts, questions, or comments regarding these articles. Email responses to westminsterpublishers@comcast.net. In the subject line, please type the journal issue and lead author such as "CLIN LAB SCI 23(3) SUPPL: RE ISABEL". Selected responses may appear in the Dialogue and Discussion section in a future issue. Responses may be edited for length and clarity. We look forward to hearing from you. 